\title{
What's the holdup on national licensing for doctors?
}

\author{
Cite as: CMAJ 2019 November 18:191:E1287-8. doi: 10.1503/cmaj.1095833
}

Posted on cmajnews.com on October 29, 2019

anada has more doctors than ever, but medical licensing rules pose a barrier to them working wherever they are most needed. Nine in 10 physicians support national licensure that would enable them to practise anywhere in the country, according to a survey of nearly 7000 doctors conducted by the Canadian Medical Association (CMA).

"It would be common sense that if I'm safe to practise in Ontario, then I should be safe to practise in British Columbia," says CMA President Dr. Sandy Buchman. However, that's not the way it works.

Although doctors undergo similar training across Canada, all 13 provinces and territories have separate licensing requirements and fees. This means that a doctor licensed in Ontario can't back up colleagues in Manitoba without repeating onerous and costly licensing processes there.

The requirement for separate licenses also limits the reach of telemedicine programs, Buchman explains. "As a palliative care physician, for example, l'd love to be able to provide virtual consultation and support to people in remote and rural Canada," he says. "Seventy percent of Canadians don't get access to palliative care."

However, like more than half of physicians surveyed by CMA, Buchman has never applied for licensure in other provinces and territories because "the barriers are great."
More than three in five doctors surveyed by the CMA said the overall complexity of the licensing process was a major obstacle to practising in other jurisdictions. More than half also cited the length of the process and the cost of getting licensed as key barriers. The fees associated with licensure can total "several thousand dollars each time they make the application," Buchman notes.

Without these barriers, "we're seeing that a lot of physicians would be willing to help out to provide virtual care and access to areas of the country in which they're not licensed," Buchman says.

Three-quarters of doctors surveyed agreed that national licensure would improve access to care. With more flexible licensing, many said they would be somewhat or highly likely to provide virtual care $(38.7 \%)$, temporarily practise in remote areas $(41.5 \%)$, and seek out locum opportunities in other jurisdictions $(45.3 \%)$.

Whether national licensure is possible remains to be seen. According to Dr. Linda

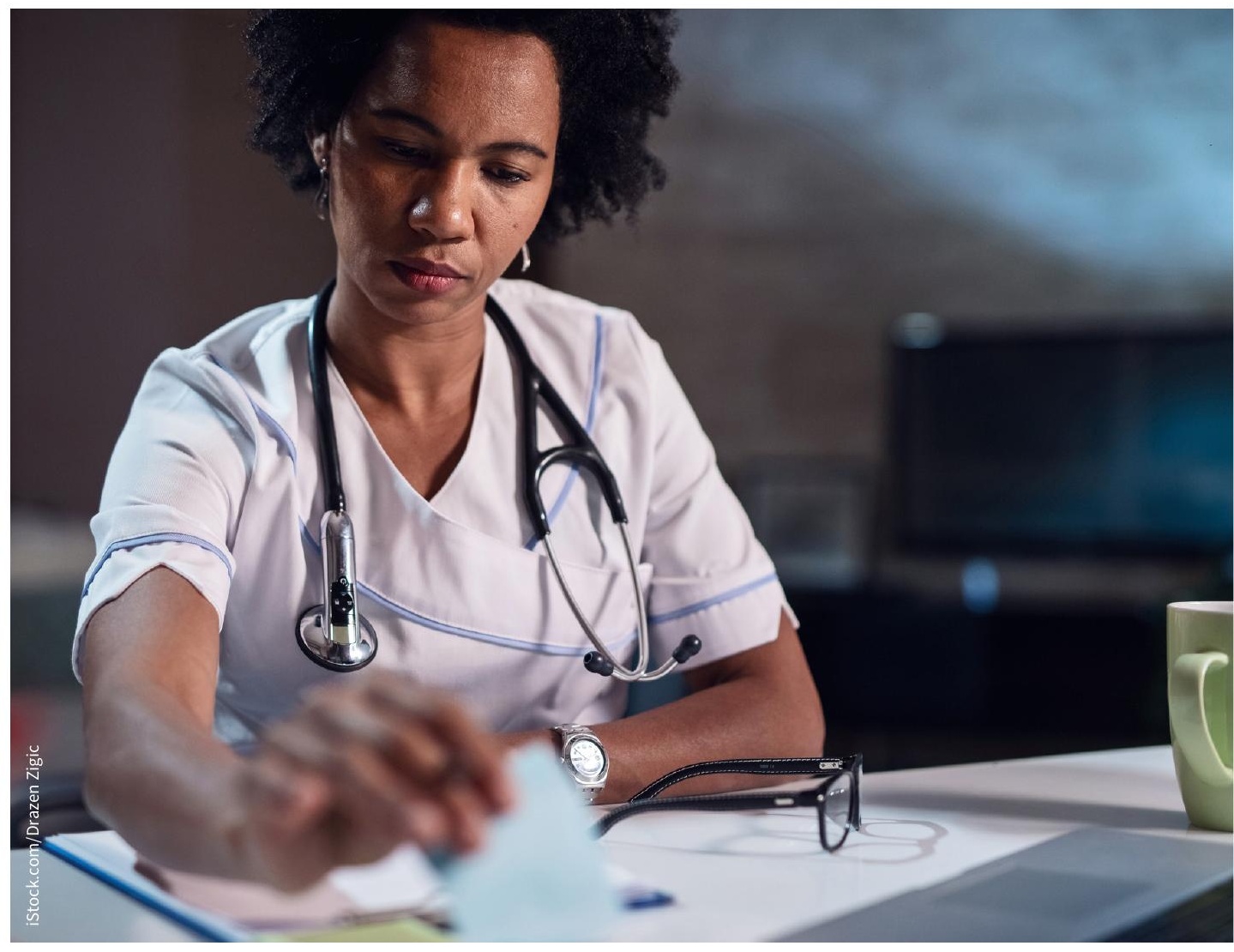

Canada's medical licensing rules require doctors to undergo onerous, costly applications to work in other provinces or territories. 
Inkpen, president of the Federation of Medical Regulatory Authorities of Canada, the hands of medical regulators are tied by Canada's constitution.

Professional regulation is a provincial responsibility, even if the standards are roughly the same in every province and territory, she explained at the CMA Health Summit in August. "We need other partners to deal with the national licensing issue."

In the meantime, Canadian medical regulatory colleges are considering an expedited clearance for temporary work in other jurisdictions that would function like a NEXUS card does for travel between Canada and the United States. They are also working on agreements that would allow doctors to provide occasional virtual care to patients outside their home province or territory without obtaining additional licenses.

Some physicians feel that regulatory colleges have resisted better solutions in order to protect their income from fees. These can add up quickly. For example, the College of Physicians and Surgeons of Nova Scotia has an annual fee of $\$ 1950$, plus $\$ 975$ for fees paid after July 1 . A temporary license costs an additional $\$ 850$. There are also fees for documentation, to review qualifications, to copy a diploma and to confirm if a physician is a member of the college.

According to Buchman, a CMA taskforce will report on next steps to national licensure in the new year.

Lauren Vogel, CMAJ 